\title{
VALORES PESSOAIS E PERCEPÇÃO DE ATRIBUTOS EM MARCAS REGIONAIS DE CAFÉ NA CIDADE DE LAVRAS
}

\author{
PERSONAL VALUES AND ATTRIBUTES PERCEPTION ABOUT \\ COFFEE REGIONAL BRANDS IN LAVRAS
}

Recebido - 11.08.10

Aceito - 12.03.2011

\begin{abstract}
Márcio Lopes Pimenta ${ }^{1}$, Marcos Hideyuki Yokoyama ${ }^{2}$, Luiz Henrique de Barros Vilas Boas ${ }^{3}$, Stella Naomi Moriguchi ${ }^{4}$ e Juliana Flávia Palazzo Macedo ${ }^{5}$
\end{abstract}

\section{Resumo}

Marcas regionais de alimentos proporcionam diferencial competitivo porque seus consumidores relacionam determinados atributos desejados com a imagem positiva da origem geográfica do produto. Tal imagem influencia o processo de decisão de compra, diante de suas percepções sobre os atributos da marca e os benefícios esperados ao consumir produtos dela derivados. Nessa visão, este trabalho evidencia a estrutura cognitiva de valores de consumidores em relação a marcas regionais de café torrado e moído na região de Lavras, Minas Gerais. Por meio de entrevistas em profundidade, utilizando a técnica qualitativa laddering, foi elaborado um mapa hierárquico de valor, que mostra uma conexão das marcas regionais aos atributos: 'Características sensoriais', 'É da região', 'Marca conhecida', 'Preço mais baixo' e 'Pureza do alimento' na percepção dos consumidores. Por meio desses atributos, os consumidores acreditam poder alcançar valores pessoais como: 'Autorrealização', 'Bem-estar próprio e da população', 'Felicidade', 'Nostalgia', 'Qualidade de vida' e 'Longevidade'.

Palavras-chave: Marcas regionais. Café torrado e moído. Laddering.

\footnotetext{
1 Professor da Universidade Federal de Itajubá (UNIFEI), doutorando em Engenharia de Produção pela Universidade Federal de São Carlos (UFSCAR). Brasil. E-mail: pimenta@fagen.ufu.br

2 Mestre em Engenharia de Produção, Universidade Federal de São Carlos (UFSCAR). Brasil. E-mail: marcosh@dep.ufscar.br.

3 Professor, Doutor, Universidade Federal de Uberlândia (UFU). Brasil. E-mail: Ihvilasboas@fagen.ufu.br.

4 Professora, Doutora, Universidade Federal de Uberlândia (UFU). Brasil. E-mail: stellanm@ufu.br.

Mestre em Administração, Universidade Federal de Uberlândia (UFU). Brasil. E-mail: jfpalazzo@hotmail.com.
} 


\begin{abstract}
Regional food brands generate competitive differential because consumer links some desired attributes with a positive image of product's geographical origin. Such image influences the buying decision process, facing their perceptions about brand attributes and desired benefits in consuming products from these brands. On this view, this paper evidences the cognitive structure of consumers of roasted and milled coffee from Lavras' region, Minas Gerais State. Based upon in depth interviews, utilizing the laddering qualitative technique, it was made a hierarchic value map, that shows a connection of the regional brands to the attributes: 'sensorial characteristics', 'from the region', 'known brand', 'lower price' and 'pureness food'. From these attributes, the consumers believe in the possibility to reach personal values as: 'self achievement', 'personal and collective wellbeing', 'happiness', 'nostalgia', 'life quality' and 'longevity'.
\end{abstract}

Keywords: Regional Brands. Toasted and milled coffee. Laddering.

\title{
1. INTRODUÇÃO
}

As marcas regionais de alimentos fornecem uma percepção de valor por meio de atributos típicos de uma determinada região geográfica e conduzem a respectivos benefícios (consequências) pelo consumo destes atributos.

Os produtos de marcas regionais se caracterizam principalmente por serem produzidos e distribuídos em regiões determinadas, sem abrangência nacional ou internacional (BRONNENBERG; DHAR; DUBE, 2007; AMA, 2009). Apesar dessa definição, alguns autores (ENKE; GEIGENMÜLLER, 2004; ORTH; WOLF; DODD, 2005) destacam a existência de empresas que as comercializam em âmbito nacional e/ou internacional, a fim de obter vantagens competitivas relacionadas à imagem positiva da origem geográfica.

Apesar de diversos autores destacarem o crescimento da preferência dos consumidores de alimento por marcas regionais, as pesquisas neste âmbito ainda são restritas (SCHLEYERBACH; ALVENSLEBEN, 1998; ENKE; GEIGENMÜLLER, 2004).

Considerando que a relação entre atributos típicos regionais e benefícios desejados pelo consumidor influencia a percepção de valor, há necessidade de se conhecer a estrutura de valores do consumidor de marcas regionais. Procedendo desta forma, pode-se compreender a percepção do consumidor durante o processo de decisão de compra. Informações sobre a estrutura cognitiva de valores desse consumidor podem subsidiar a elaboração de estratégias mercadológicas e o desenvolvimento de novos produtos, o que representaria benefícios aos fabricantes e aos varejistas que trabalham com marcas regionais.

Embasado nessa visão, o presente artigo tem como objetivo evidenciar a estrutura cognitiva de valores de consumidores em relação a marcas regionais de café na região de Lavras, Minas Gerais. Especificamente, pretende-se revelar os atributos, consequências e valores que caracterizam as percepções do consumidor e as respectivas conexões entre estes elementos, por meio da elaboração de um mapa hierárquico de valor. Para isso, adota-se a perspectiva da Cadeia de Meios-fim (GUTMAN, 1982), em conjunto com a técnica laddering (REYNOLDS; GUTMAN, 1988), que orienta a coleta, análise e interpretação de dados de campo.

Além desta introdução que explana sobre tema, problemática e objetivos, seguem os tópicos: 'referencial teórico', que trata das definições literárias sobre marcas regionais. Após, seguem os 'aspectos metodológicos', que expõem o procedimento de pesquisa e as características da técnica laddering. Os 'resultados' e 'considerações finais' apresentam a interpretação dos dados de campo, bem como sua relação com os objetivos propostos. 


\section{REFERENCIAL TEÓRICO}

Vários autores apontam que consumidores de alimentos demonstram crescente preferência por produtos em razão de características típicas de determinadas regiões de origem. Essa relação entre origem e características desejadas pode incrementar níveis de lealdade a marcas regionais (SCHLEYERBACH; ALVENSLEBEN, 1998; ENKE; GEIGENMÜLLER, 2004). Palumbo e Herbig (2000) ressaltam que a escolha por uma marca está relacionada com o desejo de ser aceito por um grupo social ou se tornar distinto deste. Estes autores também acreditam que marcas conhecidas podem prover confiança, familiaridade e redução de riscos na compra e no consumo.

Alguns autores sugerem que o consumidor relaciona atributos desejados de qualidade com produtos e marcas de determinadas regiões. Portanto, estas marcas passam a ser um fator de influência na decisão de compra de determinados grupos (LEWIS; STUBBS, 1999; ENKE; GEIGENMÜLLER, 2004; ORTH; WOLF; DODD, 2005).

Os consumidores se interessam por marcas regionais, considerando que estas possuem uma imagem positiva e proveem segurança e tranquilidade no consumo, por convergirem com valores e preferências comuns na região (ALAVOINE-MORNAS, 1997; ENKE; GEIGENMÜLLER, 2004).

Para Orth, Wolf e Dodd (2005), a relação entre origem do alimento e os valores pessoais dos consumidores se classificam em diversas dimensões. Esses autores realizaram uma pesquisa sobre a relação de marcas de vinho, destacando sua origem e a percepção de atributos pelos consumidores. Identificaram as dimensões: qualidade, preço, aceitação social, equilíbrio emocional, proteção ambiental e bem-estar da humanidade. Dessa forma, essas dimensões englobam elementos que compõem a estrutura de atributos do produto e sua relação com valores pessoais do consumidor.

As marcas regionais se caracterizam por possuírem distribuição em algumas regiões, mas não abrangerem todo o território nacional. Marcas locais são aquelas confinadas em um determinado mercado geográfico (BRONNENBERG; DHAR; DUBE, 2007; AMA, 2009). Além dessa definição, outros autores definem que as marcas regionais são dotadas de atributos típicos de um determinado país ou região, sendo reconhecidas em diversas regiões geográficas por tais características peculiares (SCHLEYERBACH; ALVENSLEBEN, 1998; ENKE; GEIGENMÜLLER, 2004; ORTH; WOLF; DODD, 2005). Nesta última definição, não há restrição geográfica quanto à distribuiçãa. Neste trabalho, são analisadas marcas conforme a primeira definição de marca regional, ou seja, relacionada à proximidade entre as regiões de produção e distribuição. Dessa forma, consistem em marcas que não abrangem o mercado nacional como um todo em termos de distribuição.

Lewis e Stubbs (1999) destacam que algumas empresas detentoras de marcas regionais adotam estratégias de expansão e passam a distribuí-las nacional ou internacionalmente. Nessa transição, nem sempre a marca continua sendo posicionada com base nos atributos típicos, preferidos em uma determinada região. Há casos em que se modificam estratégias de produto e de propaganda para evidenciar características diferentes do mesmo produto, em regiões diferentes. Em complemento, Enke e Geigenmüller (2004) argumentam que as marcas regionais podem realmente ser reconhecidas e valorizadas em mercados globais. Entretanto, devese observar que, nesta perspectiva, as marcas regionais podem ser meros complementos ao portfólio de marcas de multinacionais. Nesse caso, a detentora, em si, não se relaciona diretamente com os atributos de regionalidade da marca. 
Os varejistas e fabricantes devem se atentar a esses produtos/marcas e à percepção do consumidor que os valorizam, para que possam atingir seus objetivos estratégicos atendendo o mercado com a qualidade necessária (ALAVOINE-MORNAS, 1997).

Alavoine-Mornas (1997) realizou uma pesquisa com consumidores de frutas e verduras frescas em pontos de varejo da França e destacou que os consumidores percebem, no alimento consumido, qualidades típicas da cultura das regiões em que habitam. Nesse sentido, os consumidores têm uma imagem de tradição, garantia de qualidade e de conhecer profundamente o produto que estão consumindo e seu processo produtivo. Além deste fato, este autor aponta a percepção de desenvolvimento da sustentabilidade da economia regional, bem como a o bemestar da população que vive em zonas rurais produtoras. Hamin e Helliot (2006) também concordam com tal percepção e destacam que alguns consumidores acreditam que comprando produtos fabricados localmente exercem uma conduta moralmente mais apropriada nesse sentido. Diante dessas constatações acerca da literatura sobre marcas regionais, obtém-se material comparativo para orientar a análise dos resultados empíricos, cujos procedimentos de coleta, análise e interpretação dos dados são detalhados no tópico seguinte.

\section{ASPECTOS METODOLÓGICOS}

Esse tópico dedica-se à exposição dos métodos utilizados para a coleta, análise e interpretação dos dados desta pesquisa, em destaque para a técnica qualitativa laddering, que foi tomada por base em tais procedimentos.

Este trabalho é parte de uma pesquisa maior, que teve seu projeto financiado pela Fundação de Amparo à Pesquisa de Minas Gerais (FAPEMIG) e envolveu o esforço de grupos de pesquisa situados em três universidades de Minas Gerais e São Paulo. Seus resultados finais devem abranger estudos deste tipo em três cidades mineiras.

Cabe destacar que o conceito de marca regional, aqui adotado, refere-se às marcas cuja distribuição está restrita a poucos estados da federação e cuja percentagem de vendas no estado de Minas Gerais seja superior a 50,0\% das vendas totais da empresa. As marcas nacionais, por sua vez, são aquelas que possuem atuação e presença significativa em vários estados da federação, conforme conceito de Kapferer (2004).

Foram realizadas 16 entrevistas em profundidade com consumidores de seis marcas de café distribuídas na região de Lavras, Minas Gerais. Somente foram entrevistadas pessoas que consumiam estes produtos há mais de seis meses, e o fazem pelo menos uma vez por mês. As entrevistas foram realizadas em quatro pontos de varejo (três supermercados e uma mercearia), em setembro de 2008, na cidade de Lavras. Todas as entrevistas foram gravadas em áudio, transcritas e submetidas a uma análise de conteúdo para agrupamento de sinônimos e atribuição de códigos de resumo para cada sinônimo. Esse procedimento teve como intuito determinar quais elementos (atributos, consequências e valores) foram percebidos pelos consumidores e quais atributos conduziam a determinadas escalas de consequências e valores.

A orientação para a coleta, interpretação e análise de dados partiu dos pressupostos da literatura sobre a laddering, que se caracteriza como uma técnica de pesquisa qualitativa utilizada por diversos pesquisadores para o estudo da estrutura de valores envolvida no processo de decisão de compra do consumidor ou da percepção de valor que este destina a um determinado produto. Neste intuito, a técnica foi utilizada pelos seguintes autores: Reynolds e Gutman 
(1988); Gutman (1991); Reynolds, Gengler e Howard (1995); Leão e Mello (2001); Veludo de Oliveira e Ikeda (2004); Ferran e Grunert (2007); Padel e Foster (2005); Vilas Boas (2005); Pimenta et al. (2007); Krystallis, Maglaras e Mamalis (2008); Pimenta (2008). A laddering segue, como base metodológica, a Teoria da Cadeia de Meios-Fim, que pressupõe que o consumidor tenha percepção de atributos, consequências e valores relacionados a um produto ou marca. Dessa forma, é necessário que o entrevistado revele naturalmente as razões para o consumo de um determinado bem ou em um determinado local (GUTMAN, 1982). Conforme Reynolds e Gutman (1988), as fases da laddering, compreendem:

- levantamento da percepção do consumidor por meio de perguntas como: "por que isto é importante para você?" de forma repetitiva, ou seja, conforme o entrevistado revele os atributos percebidos, é questionado sobre tal importância até que revele os valores pessoais relacionados com esses atributos. Por meio dessas questões repetitivas, pode-se destacar quais as razões da importância de um atributo na percepção do consumidor;

- $\quad$ análise de conteúdo e padronização dos termos identificados (Códigos) na entrevista. Distinção entre atributos, consequências e valores. No item sobre os resultados da pesquisa (item 4), os códigos são denominados sinônimos, em adequação à literatura nacional;

- construção de uma tabela (matriz de implicação), representando a quantidade de conexões entre os códigos, ou seja, quantas vezes cada elemento leva ao alcance de cada atributo, consequência ou valor. Esta tabela contabiliza as relações diretas e indiretas entre esses elementos, formando coordenadas que servirão para a construção do mapa hierárquico de valor;

- a partir desta matriz, constrói-se um mapa hierárquico de valor (MHV), que corresponde a um diagrama em forma de árvore e representa graficamente as conexões ou associações entre os atributos, consequências e valores levantados nas entrevistas.

Na etapa da construção do MHV deve ser definido o ponto de corte que pode variar de acordo com a quantidade de relações entre atributos, consequências e valores obtidos. Tal variação deve ser relativa frente à frequência de relações encontradas na análise de conteúdo. Toma-se, dessa forma, a recomendação de Reynolds e Gutman (1988) sobre o ponto de corte, que deve abranger entre 75 e $80 \%$ dos relacionamentos mostrados na matriz de implicação. Dessa forma, não são destacados os relacionamentos com baixa incidência e, por consequência, não significantes. Além dessa recomendação, sugere-se que o mapa tenha clareza suficiente para facilitar a visualização das principais cadeias (REYNOLDS; GUTMAN, 1988; MAKATOUNI, 2002; VILAS BOAS, 2005; PIMENTA, 2008). Diante dessas recomendações, foi utilizado o ponto de corte 2, que abrangeu $74,5 \%$ das relações e proveu um MHV coerente, composto de elementos de incidência igual ou maior a 2. Segundo Reynolds e Gutman (1988), o último passo da análise é identificar as orientações de valor dominante, ou seja, quais cadeias são mais relevantes do MHV, no intuito de observar quais foram as que mais contribuíram para o resultado.

Em auxílio ao uso da laddering, o software Mecanalyst colaborou para facilitar o processo de codificação dos elementos, organização dos dados e construção das estruturas de análise que caracterizam a técnica. O Mecanalyst foi utilizado para a construção da matriz de implicação e do mapa hierárquico de valores, visto que também foi adotado por vários autores em trabalhos sobre comportamento do consumidor de alimentos (NASPETTI; ZANOLI, 2004; ROININEN; ARVOLA; LÄHTEENMÄKI, 2006; KRYSTALLIS; MAGLARAS; MAMALIS, 2008; PIMENTA, 2008; MACEDO, 2009). 


\section{RESULTADOS}

Diante do procedimento da laddering, explanado no tópico sobre a metodologia, foi possível identificar 26 sinônimos, classificados em 6 atributos, 13 consequências e 7 valores. Esses sinônimos são espécies de códigos de agrupamento das opiniões dos consumidores sobre os atributos dos cafés de marca regional e sua relação com seus valores pessoais. O quadro 1 mostra esses sinônimos e sua classificação como atributos, consequências e valores.

\begin{tabular}{llllll}
\hline \multicolumn{1}{c}{ Atributos } & \multicolumn{1}{c}{ Consequências } & \multicolumn{2}{c}{ Valores } \\
\hline 1 & Características sensoriais & 7 & Confiança na marca & 20 & Auto realização \\
2 & É da região & 8 & Consumir mais quantidade & 21 & Bem-estar \\
3 & Marca conhecida & 9 & Desenvolvimento econômico regional & 22 & Bem-estar da população \\
4 & Preço mais baixo & 10 & Disposição & 23 & Felicidade \\
5 & Pureza do alimento & 11 & Economia de dinheiro & 24 & Nostalgia \\
6 & Qualidade & 12 & Não gastar com médico e remédio & 25 & Qualidade de vida \\
& 13 & Poder comprar outras coisas & 26 & Viver mais \\
& 14 & Prazer em se alimentar & & \\
& 15 & Produção cuidadosa & & \\
& 16 & Satisfação & & \\
& 17 & Saúde & & \\
& 18 & Segurança & & \\
& 19 & Valoriza a terra onde nasci & & \\
& & & & \\
\end{tabular}

\section{Quadro 1 - Atributos consequências e valores identificados}

Fonte: dados da pesquisa

O atributo 1 (características sensoriais) representa o sabor e o aroma do café de marca regional, que segundo os consumidores é mais forte e encorpado que as marcas nacionais. $\mathrm{O}$ café que é produzido, embalado e distribuído regionalmente é representado pelo atributo 2 . O atributo 3 representa a familiaridade do consumidor com a marca. Preços mais acessíveis são percebidos pelos consumidores destes produtos (atributo 4). A pureza do alimento corresponde à ausência ou presença reduzida de misturas e impurezas (cereais, galhos, grãos de café inferiores) que possam impactar o sabor e o aroma. A qualidade, representada pelo atributo 6, corresponde à adequação da moagem e da torrefação, ambas em médio nível para não prejudicar a economia e o paladar (em tom marrom claro para não ficar muito amargo).

Em relação às consequências, a confiança que o consumidor deposita na marca é representada pela consequência 7. Por diferentes razões, o consumidor é motivado a consumir mais quantidades (consequência 8). Há uma preocupação entre os consumidores com o desenvolvimento econômico e social da região, representada pela consequência 9. Há desejo por disposição, que representa a necessidade de maior rendimento no trabalho e nas atividades pessoais (consequência 10). Esses consumidores desejam consequências como: economizar dinheiro, não gastar com médico e remédio, comprar itens não rotineiros (carros, itens de lazer, viagens, outros alimentos) e também prezam pelo alcance de prazer na alimentação. A produção cuidadosa representa um conhecimento prévio dos consumidores sobre o processo produtivo da empresa, que deve ser higiênico e claro quanto às misturas de outros elementos ao café. A consequência 16 representa a sensação de saciedade e a capacidade de se manter desperto, que o café deve proporcionar. Também os consumidores desejam obter saúde e segurança 
(ausência de insegurança quanto à procedência e qualidade ruim). A consequência 19 (valorizar a terra em que nasci) representa aspectos emocionais, não econômicos que ligam a preferência do consumidor à origem da marca.

Dos valores pessoais identificados, o 20, autorrealização, representa a sensação de sentir-se útil, autossuficiente, reconhecido e atingir objetivos pessoais; e o 21, bem-estar, corresponde à busca de prazer na vida própria e da família. O valor 22 representa a preocupação com a saúde, a cultura, o estudo, a economia e o bem-estar geral da sociedade regional, em prol de um melhor local para se viver. Os valores 23 (felicidade) e 24 (nostalgia) significam uma valorização de estados pessoais de alegria e a busca por elementos da vida na infância/juventude, principalmente pessoas que foram criadas na zona rural e relacionam cafés regionais a esse contexto. O valor 25 (qualidade de vida) representa a busca por lazer, ausência de rotina, frequentar bares e restaurantes. O valor 26 representa a valorização da longevidade.

Apresentados esses sinônimos e suas respectivas classificações em atributos, consequências e valores dos consumidores de cafés de marcas regionais, cabe agora demonstrar a ligação entre cada elemento por meio da matriz de implicação, destacada na tabela 1. A matriz de implicação identifica as ligações perceptivas entre os elementos expostos no quadro 1, bem como sua representação numérica, que implica na incidência de respostas a respeito de cada uma das ligações. A matriz de implicação permite a análise numérica das relações entre os elementos (atributos, consequências e valores) e fornece coordenadas para a construção do mapa hierárquico de valor, que consiste em um diagrama que mostra as sequências de relações formadas pelas escalas (ladders) de elementos coligados.

Conforme exposto na metodologia, a matriz de implicação consiste em uma estrutura de colunas e linhas, sendo uma coluna e uma linha para cada elemento (sinônimo) codificado, de forma sequencial a partir da numeração de códigos atribuída. Corresponde à representação das escalas (ladders) de elementos que foram obtidos por meio das entrevistas e da análise de conteúdo. Cada célula contém a quantidade de vezes que um elemento leva a outro, de forma direta ou indireta. De acordo com Reynolds e Gutman (1988), as ligações diretas correspondem àquelas em que um elemento está diretamente ligado a outro. As células são preenchidas com o número de relações diretas à esquerda, e o número de relações indiretas à direita, ou seja, trata-se de uma contabilização de quantas vezes um elemento recebeu ligações diretas (do lado esquerdo da célula) ou indiretas (do lado direito da célula), representando uma quantificação dos dados qualitativos. As ligações diretas, ao lado esquerdo das células, representam as ligações adjacentes entre os elementos.

\subsection{Análise e interpretação do mapa hierárquico de valor}

As ligações diretas e indiretas observadas na matriz de implicação permitiram formar as escalas de sinônimos e o conjunto destas escalas permitiu formar as cadeias que compõem o mapa hierárquico de valor, exposto na figura 1. O referido mapa é composto de 48 cadeias que partem de 6 atributos, passam por 12 consequências e atingem 7 valores. A relação entre estes elementos formou um total de 274 ligações. Com a utilização do ponto de corte 2, justificado na metodologia deste trabalho, foi possível abranger 74,5\% das ligações, totalizando 204 ligações efetivamente expostas no mapa. Os atributos são identificados pelos retângulos de cor clara; os valores, em cor escura; e as consequências, em cor mediana.

Podem-se observar, no mapa, as 7 cadeias formadas pelo atributo 1 (características sensoriais), na qual o consumidor busca um café mais forte, sem gosto de impurezas, com a cor 
marrom-claro e cheiro forte. As cadeias 1-5-14-16-10-23 e 1-5-14-16-10-20 mostram a relação deste atributo com o prazer em se alimentar, a busca de disposição, alcance de felicidade e autorrealização. As cadeias 1-5-14-8-10-20 e 1-5-14-8-10-23 mostram o desejo de alcançar felicidade e autorrealização, por haver motivação em consumir maiores quantidades de um café que tenha aroma e paladar fortes. Há uma ligação bastante forte entre essas características sensoriais e a consequência 14, que representa o prazer em se alimentar. A cadeia 1-5-14-21 constata o desejo do consumidor em alcançar bem-estar (tranquilidade, prazer pessoal, conforto, pessoal e da família). Tal consumidor percebe que este estado é proporcionado pelo prazer na alimentação, que é possível por meio de um alimento mais puro (sem misturas ou impurezas), que, consequentemente, tem um sabor melhor (mais forte). A cadeia 1-5-11-13-21 também mostra a conexão entre as características sensoriais e bem-estar, porém utilizando-se de outro caminho: a pureza do alimento. Segundo esses consumidores, se o café não possuir misturas e impurezas, haverá um gasto menor de pó ao prepará-lo e, consequentemente, economia de dinheiro, que possibilita a compra de itens não rotineiros. As características sensoriais também levam ao alcance do valor "nostalgia", que se refere à lembrança dos tempos de infância e juventude de pessoas que moraram na zona rural. Isso se dá em razão do aspecto, cor marron-claro, gosto forte e puro do café regional, que o faz parecer com o café "da roça" ou "com sabor mineiro", segundo os consumidores. Tal situação é mostrada pela cadeia 1-24. Essas cadeias denotam convergência com a opinião de autores (LEWIS; STUBBS, 1999; ENKE; GEIGENMÜLLER, 2004; ORTH; WOLF; DODD, 2005) que citam a percepção do consumidor de que marcas regionais estão relacionadas com certos atributos típicos da região (sabor, forte, sabor da fazenda, remete aos tempos de infância).

A partir do atributo 2 (É da região) são geradas 13 cadeias, que representam a preocupação dos consumidores com o aspecto regional, suas características produtivas e seus impactos sociais. Estes aspectos convergem com a opinião de Alavoine-Mornas (1997) e Orth, Wolf e Dodd (2005). A cadeia 2-9-22 mostra o desejo por uma sociedade mais justa, com mais empregos e o bem-estar geral da sociedade, que é alcançado pelo desenvolvimento econômico da região gerado pela produção local. A produção local também beneficia a qualidade de vida, conforme destaca a cadeia 2-9-25. As cadeias 2-15-17-12-25 e 2-15-17-26 mostram a percepção do consumidor de que os produtos da região têm a produção cuidadosa em termos de higiene de processo e matéria-prima, e esses itens proporcionam saúde.

A saúde leva as pessoas a tomarem menos remédios e a obterem qualidade de vida. Leva também ao alcance de uma vida mais longa. As cadeias 2-15-17-21, 2-15-17-10-20 e $2-$ 15-17-10-23 denotam a percepção de que produtos regionais são benéficos à saúde, que proporciona bem-estar (busca de prazer pessoal e da família) e disposição no trabalho e nas atividades pessoais, como também acreditam Orth, Wolf e Dodd (2005). Tal disposição gera uma vida mais alegre e realizações pessoais (atingir objetivos, reconhecimento, não depender dos outros para se cuidar na velhice ou na doença). A principal cadeia gerada pelo atributo 2 consiste em 2-7-17-21, pois possui uma incidência alta de respostas, por isso é considerada uma cadeia dominante, ou seja, com alta capacidade explicativa do comportamento do consumidor de marcas regionais de café. As cadeias dominantes são representadas pelas linhas mais espessas no mapa. Nessa cadeia observa-se uma forte percepção de que os cafés regionais são dignos de confiança na marca, proporcionam saúde, e essa saúde gera bem-estar.

Nas cadeias 2-7-17-12-25, 2-7-17-26, 2-7-17-10-20 e 2-7-17-10-23 o consumidor mostra preocupação em alcançar valores como longevidade, autorrealização e felicidade, por meio de produtos regionais, considerados mais confiáveis e saudáveis. A cadeia 2-7-18-21 mostra a preferência por marcas de café regionais por serem mais confiáveis, emitirem segurança e, por 


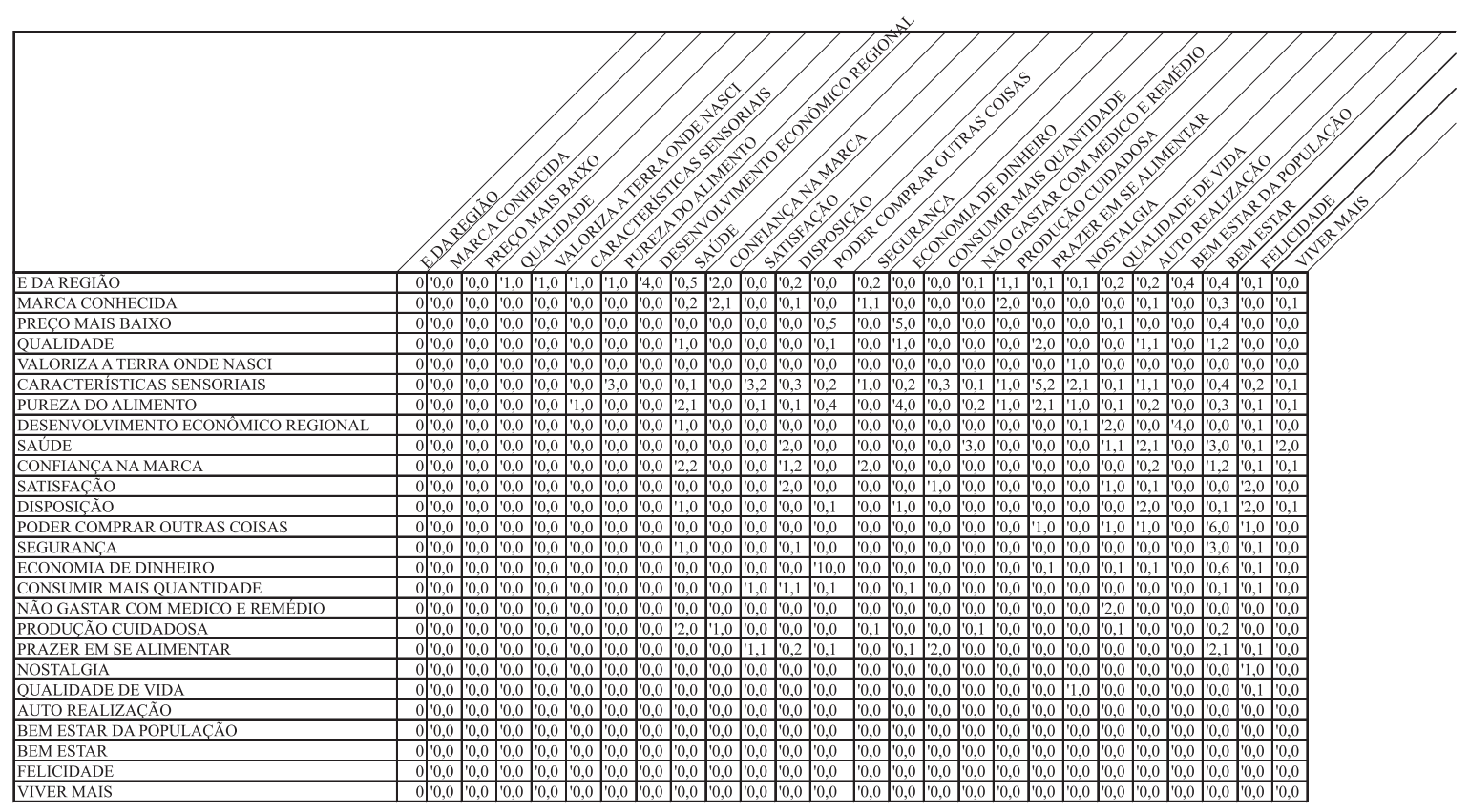

Tabela 1 - Matriz de implicação

Fonte: Dados da pesquisa.

isso, proporcionarem bem-estar. Dessa forma, nota-se convergência com as motivações expostas por Palumbo e Herbig (2000) para o consumo dessas marcas. Esse conjunto de cadeias iniciadas pelo atributo 2 também podem ser iniciadas pelo atributo 3 (marca conhecida), pois esse atributo influencia a confiança na marca (consequência 7) e imprime uma imagem de produção cuidadosa (consequência 15). Dessa forma contribuem para a formação das cadeias expostas pelo atributo 2, com exceção de 2-9-22 e 2-9-25, totalizando 11 cadeias.

O atributo 4 (preço mais baixo) forma a cadeia mais representativa do mapa, sendo considerada uma cadeia dominante na explicação da percepção desse consumidor. Este atributo forma apenas uma cadeia: 4-11-13-21, e corresponde ao alcance de bem-estar (prazer pessoal e da família) por meio da possibilidade de comprar itens diversificados e não rotineiros. Essa compra extra é proporcionada pela economia de dinheiro gerada pelos preços mais baixos que têm os produtos de marca regional. O atributo 5 (pureza do alimento) representa a percepção de que o café de marca regional rende mais no preparo, reduzindo o gasto de pó. Além disso, não possui impurezas ou misturas (galhos folhas, cereais) e, por esse motivo, é um café mais concentrado e saboroso. Muitos consumidores têm a percepção de que não há impurezas e misturas nessas marcas regionais, o que não significa que isso efetivamente ocorra. O consumidor tem uma visão negativa da presença desses componentes em relação aos benefícios que um produto com maiores teores de café puro pode oferecer. A principal cadeia gerada por esse atributo consiste em 5-11-13-21, considerada como uma cadeia dominante pela alta incidência das ligações que a compõe. Esta cadeia mostra a preocupação do consumidor com um alimento mais puro, sem misturas, de modo a alcançar maior rendimento no preparo e economia de dinheiro. Com essa economia poderá comprar outros itens não rotineiros e obter estados de bem-estar pessoal e familiar. Também há uma forte relação desse atributo com a consequência 14 (prazer em se alimentar), pois alimentos mais puros são mais saborosos e levam ao prazer na degustação. Esse prazer da degustação proporciona disposição, que conduz a momentos de 
felicidade e ao alcance de autorrealização por melhorarem o alcance de objetivos no trabalho e na vida pessoal. O prazer em se alimentar também gera bem-estar.

As cadeias 5-14-16-10-23, 5-14-16-10-20, 5-14-8-10-23, 5-14-8-10-20 e 5-14-21 demonstram tais percepções. A percepção sobre a pureza do alimento também pode levar à consequência 5 (saúde), que tem forte relação com o alcance de bem-estar (valor 21), destacado na cadeia 5-17-21. As cadeias 5-17-12-25, 5-17-26, 5-17-10-20 e 5-17-10-23 representam um consumidor que, preocupado com alimentos mais puros, busca saúde para obter felicidade, autorrealização, qualidade de vida e longevidade.

As cinco cadeias formadas a partir do atributo 6 (qualidade) identificam a busca do consumidor por prazer pessoal, alcance de objetivos pessoais e autossuficiência (não depender dos outros na velhice ou em estados de enfermidade). Os consumidores definiram a qualidade do café regional como sendo um alimento mais novo na gôndola, ou seja, passa menos tempo entre a fabricação, transporte e supermercado, pela proximidade do ponto de varejo e a fábrica.

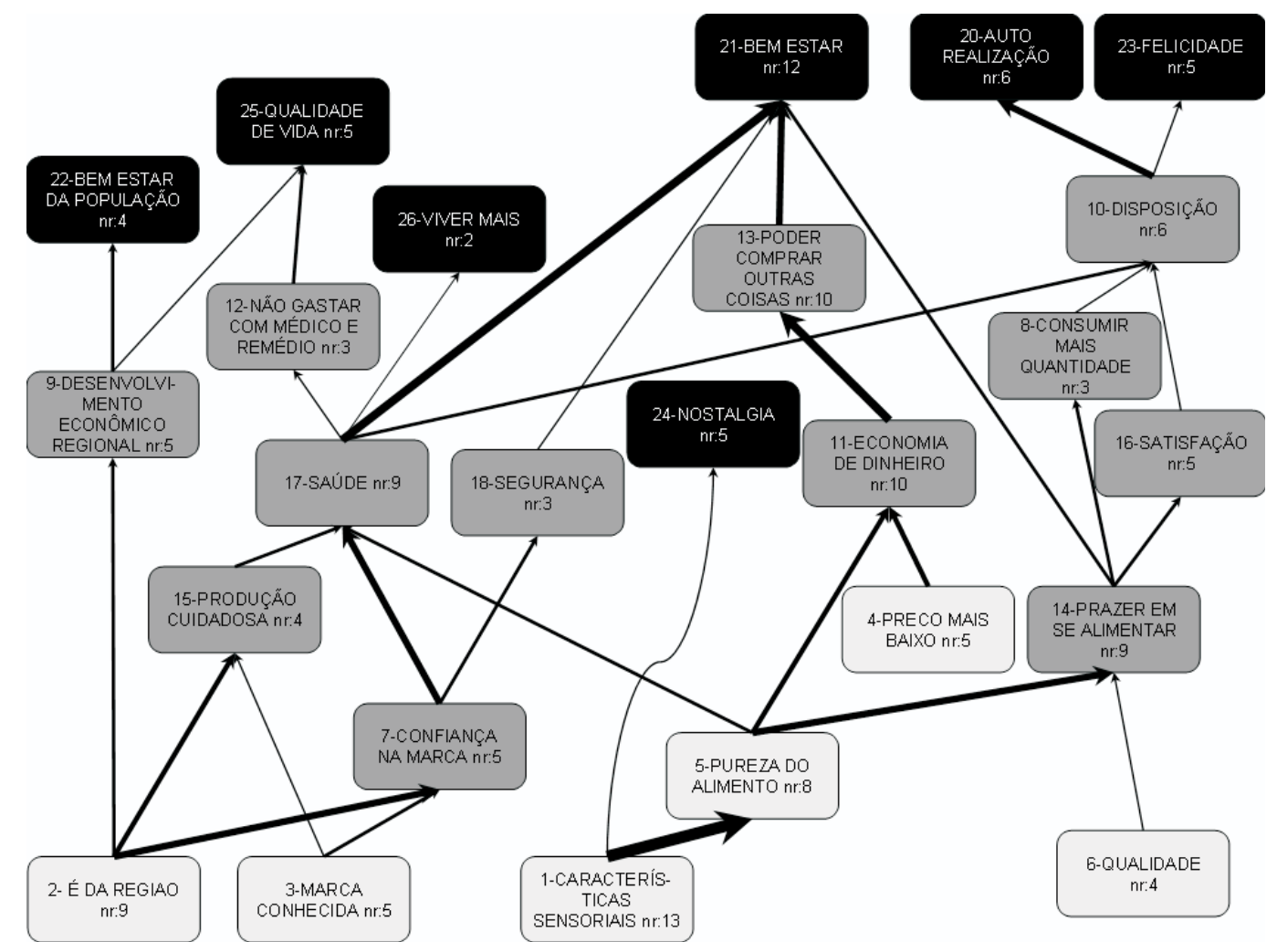

Figura 1 - Mapa hierárquico de valor

Além disso, acreditam que este produto possui mais nutrientes e gorduras que as marcas nacionais. Tais afirmações são baseadas nas cadeias: 6-14-16-10-23, 6-14-16-10-20, 6-14-810-23, 6-14-8-10-20 e 6-14-21. Diante dos resultados aqui destacados foi elaborado o quadro 2 , que mostra os atributos identificados na pesquisa e o significado de suas relações com os valores pessoais dos consumidores entrevistados. 


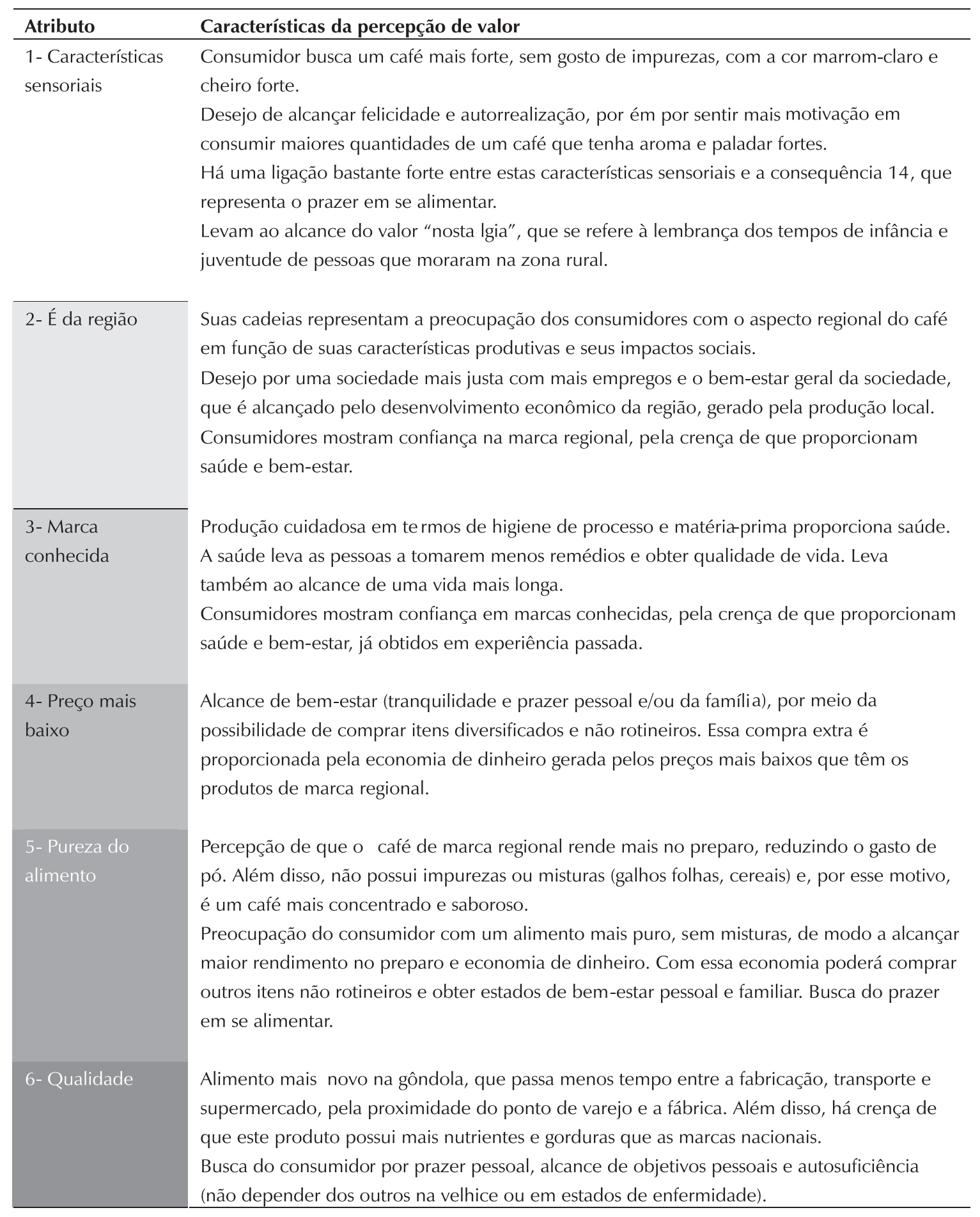

\section{Quadro 2 - Principais ligações entre atributos e valores identificados}

Fonte: Dados da pesquisa

O quadro 2 resume o conteúdo das cadeias que compõem o mapa hierárquico de valor, apresenta os atributos identificados e suas respectivas ligações de valor na percepção do consumidor de marcas regionais de café em Lavras, MG. Na análise do mapa hierárquico de valor, nota-se claramente que o consumidor identifica que a marca é regional e percebe, ainda, 
que esta tem ligações com sabor de sua preferência e preço mais baixo. Cadeias dominantes formadas principalmente pelos atributos "características sensoriais" e "É da região". Essas cadeias e as formadas pelos demais atributos dispostos no mapa evidenciam a relação das marcas regionais de café com os valores pessoais dos consumidores.

\section{Considerações finais}

A análise dos resultados leva a concluir que, para alguns consumidores de café torrado e moído em Lavras, MG, existe relação da marca regional como determinante de compra. Esses consumidores, além de perceberem-nas como sendo regionais, identificam preferências por atributos e consequências encontrados especificamente nessas marcas. Além disso, valores pessoais podem ser alcançados por meio das características percebidas nessas marcas regionais, como se pode observar nas cadeias do mapa hierárquico de valor, principalmente as iniciadas pelos atributos "é da região", "características sensoriais", "pureza do alimento" e "preço mais baixo", que formam cadeias dominantes.

Percebe-se que o grupo de consumidores entrevistados prefere um café que tenha aroma e paladar fortes, sem gosto de palha ou impurezas, cor marrom clara e aspecto mais encorpado (atributos 1 e 5). Esses atributos formam cadeias dominantes, com alta capacidade de explicação do comportamento do consumidor. O atributo 5, "pureza do alimento", destaca a preocupação do consumidor com um alimento mais puro, sem misturas, de modo a alcançar maior rendimento no preparo e economia de dinheiro. Com essa economia, poderá comprar outros itens não rotineiros e obter estados de bem-estar pessoal e familiar.

A principal cadeia gerada pelo atributo 2 consiste em 2-7-17-21, também considerada uma cadeia dominante, mostra que o consumidor confia mais na marca que é regional por proporcionar mais saúde e, consequentemente, bem-estar pessoal. O atributo 4 (preço mais baixo) forma a cadeia mais representativa do mapa, sendo considerada também como uma cadeia dominante. Este atributo forma apenas uma cadeia, 4-11-13-21, e corresponde ao alcance de bem-estar (prazer pessoal e da família), por meio da possibilidade de comprar itens diversificados e não rotineiros. Essa compra extra é proporcionada pela economia de dinheiro gerada pelos preços mais baixos que têm os produtos de marca regional. Além dessas cadeias cabe destacar uma ligação bastante forte entre as características sensoriais e a consequência 14, que representa o prazer em se alimentar.

Diante dessas constatações, sugere-se que gerentes industriais, bem como gerentes de pontos de varejo que trabalhem com esse tipo de marca, atentem para estes pontos valorizados pelo consumidor. Dessa forma, podem tomar base nesses conceitos na intenção de aprimorar estratégias de marketing de produto, embalagem, merchandising, bem como no desenvolvimento de novos produtos. Além dessas questões práticas, sugere-se que sejam realizadas novas pesquisas que tomem por base as constatações aqui apresentadas sobre as percepções deste perfil de consumidor em outras localidades ou com outros tipos de produtos de marcas regionais.

Em termos metodológicos, este trabalho mostra uma visão aprofundada da relação entre as marcas regionais e a percepção do consumidor. Podem ser realizadas pesquisas com métodos quantitativos, com amostras maiores em regiões, de modo a destacar com maior abrangência o fenômeno da preferência por marcas regionais. 


\section{REFERÊNCIAS BIBLIOGRÁFICAS}

ALAVOINE-MORNAS, Françoise. Fruit and vegetables of typical local areas: consumers' perception and valorization strategies through distributors and producers. In: EAAE SEMINAR, 52. 1997, Parma. Anais...Parma: EAAE, 1997. p.317-329.

AMA. American Marketing Association. Disponível em: <http://www.marketingpower.com/_layouts/ Dictionary.aspx?dLetter $=\mathrm{R}>$. Acesso em: 15 abr. 2009.

BRONNENBERG, B. J.; DHAR, S.K.; DUBE, J.-P.. Consumer packaged goods in the United States: National Brands, Local Branding. Journal of Marketing Research. v.44, n.1. p. 4-13, 2007.

ENKE, M.; GEIGENMÜLLER, A. Truly global? The relevance of regional brands in an enlarged european market. In: IFSAM WORLD CONGRESS, 7., 2004, Gothenburg. Proceedings... Gothenburg: IFSAM, 2004. Cd-Room.

FERRAN, Florence de; GRUNERT, Klaus G. French fair trade coffee buyers purchasing motives: an exploratory study using means-end chains analysis. Food Quality and Preference, v. 18, n. 2, p. 218229, 2007.

GUTMAN, J. A means end chain model based on consumer categorization processes. Journal of Marketing, v .46, n. 2, p.60-72, Spring 1982.

GUTMAN, J. Exploring the nature of linkages between consequences and values. Journal of Business Research, New York, v. 22, n. 2, p.143148, 1991.

HAMIN; ELLIOTT, G. A less-developed country perspective of consumer ethnocentrism and "country of origin" effects: Indonesian evidence. Asia Pacific Journal of Marketing and Logistics, v. 18, n. 2, p. 7992, 2006

KAPFERER, Jean-Noël. As marcas, capital da empresa: criar e desenvolver marcas fortes. 3. ed. Porto Alegre: Bookman, 2004.

KRYSTALLIS, A.; MAGLARAS, G.; MAMALIS, S. Motivations and cognitive structures of consumers in their purchasing of functional foods. Food Quality and Preference, n.19. p.525-538, 2008.
LEÃO, A.L.M.S.; MELLO, S.C.B. Estratégias de comunicação através do conhecimento dos valores dos usuários: aplicação do modelo Meccas para um jornal on-line. In: CONGRESSO BRASILEIRO DE CIÊNCIAS DA COMUNICAÇÃO, 24., 2001. Campo Grande. Anais... Campo Grande: Intercom, 2001. Cd-Room.

LEWIS, Chris; STUBBS, Sara. National expansion of british regional brands: parallels with internationalization. Journal of Product \& Brand Management,v.8, n.5, p.369-386, 1999.

MACEDO, J. F. P. da C. Marcas regionais de alimentos: a relação de valor do consumidor como determinante de compra. Dissertação (Mestrado em Administração)-Universidade Federal de Uberlândia, Uberlândia, 2009.

MAKATOUNI, A. What motivates consumers to buy organic food in the UK? Results from a qualitative study. British Food Journal, Bradford, v. 104, n. 3-5, p. 345-352, 2002.

NASPETTI, S.; ZANOLI, R. Do consumers care about where they buy organic products? A means-end study with evidence from italian data. In: BAOURAKIS, G. (Ed.). Marketing trends for organic food in the $21^{\text {st }}$ century. Cingapura: World Scientific, 2004. p.238255. v. 3

ORTH, U.R.; WOLF, M. M.; DODD, T. H. Dimensions of wine region equity and their impact on consumer preferences. Journal of Product \& Brand Management, v.14, n. 2, p.88-97, 2005.

PADEL, S.; FOSTER, C. Exploring the gap between attitudes and behaviour: understanding why consumers buy or do not buy organic food. British Food Journal, Bradford, v. 107, n. 8, p. 606-625, 2005.

PALUMBO, F; HERBIG, P. The multicultural context of brand loyalty. European Journal of Innovation Management, v. 3, n. 3, p. 116-124, 2000.

PIMENTA, M.L. Comportamento do consumidor de alimentos orgânicos na cidade de Uberlândia: um estudo com base na cadeia de meios e fins. 2008. 125 f. Dissertação (Mestrado em Administração) Universidade Federal de Uberlândia, Uberlândia, 2008. 
PIMENTA, M. L.; VILAS BOAS, L.H.B.; MELO, D.C.; NUNES, E.F.; BOAVENTURA, E. A Percepção de valores na seleção de lojas do varejo alimentar: uma investigação empírica nas cidades de Uberlândia e Uberaba. In: ENCONTRO DA ANPAD, 31., 2007, Rio de Janeiro. Anais... Rio de Janeiro: Anpad, 2007. Cd-Room.

REYNOLDS, T. J.; GENGLER, C.E.; HOWARD, D. J. A means-end analysis of brand persuasion through advertising. International Journal of research in marketing, v.12, n. 3, p.257-266, out. 1995.

REYNOLDS, T. J.; GUTMAN, J. Laddering theory, method, analysis and interpretation. Journal of Advertising Research, New York, v. 28, n. 1, p. 1131, fev./mar. 1988.

ROININEN, K.; ARVOLA, A.; LÄHTEENMÄKI, L. Exploring consumers perceptions of local food with two different qualitative techniques: laddering and word association. Food Quality and Preference, Oxford, v.17, n. 1-2, p. 20-30. jan./mar. 2006.

SCHLEYERBACH, K.; ALVENSLEBEN, v. R. The problem of labeling and branding regional products. In: AIR-CAT WORKSHOP "Consumer Preferences for Products of the Own Region/Country and Consequences for the Food Marketing", 4. 1998, Ås. Anais... Ås: Matforsk 1998. p. 77-89.

VELUDO DE OLIVEIRA, T. M. ; IKEDA, A. A. Usos e limitações do método laddering. Revista de Administração, São Paulo, v. 5, n. 1, p. 197-222, 2004.

VILAS BOAS, L.H.B. Comportamento do consumidor de produtos orgânicos: uma análise na perspectiva da teoria da cadeia de meios e fins. 2005. $222 \mathrm{f}$. Tese (Doutorado em Administração)-Universidade Federal de Lavras, Lavras, 2005. 